\title{
Renal Intramedullary Infusion of Tempol Normalizes the Blood Pressure Response to Intrarenal Blockade of Heme Oxygenase-1 in Angiotensin II-Dependent Hypertension
}

\author{
David E. Stec ${ }^{1,}{ }^{*}$, Luis A. Juncos ${ }^{2}$, and Joey P. Granger ${ }^{1}$ \\ ${ }^{1}$ Department of Physiology \& Biophysics, Cardiovascular-Renal Research Center, University of \\ Mississippi Medical Center, 2500 North State St, Jackson, MS 39216 \\ ${ }^{2}$ Department of Medicine, Division of Nephrology, University of Mississippi Medical Center, 2500 \\ North State St, Jackson, MS 39216
}

\section{Abstract}

Background-Previous studies have demonstrated that intramedullary inhibition of heme oxygenase-1 (HO-1) increases the blood pressure and superoxide production response to angiotensin II (Ang II) infusion. The current study was designed to test the hypothesis that increased renal medullary superoxide production contributes to the increase in blood pressure in response to blockade of renal medullary HO-1 in Ang II-induced hypertension.

Methods-Male C57BL/6J mice (16-24 weeks of age) were implanted with chronic intrarenal medullary interstitial (IRMI) and infused with: saline, Tempol (6mM), the HO-1 inhibitor QC-13 $(25 \mu \mathrm{M})$, or a combination of tempol + QC-13. Tempol treatment was started 2 days before infusion of QC-13. After 2 days, Ang II was infused subcutaneously at at a rate of $1 \mu \mathrm{g} / \mathrm{kg} / \mathrm{min}$ for 10 days.

\begin{abstract}
Results-Blood pressures on days 7-10 of Ang II infusion alone averaged $150 \pm 3 \mathrm{mmHg}$ in mice receiving IRMI infusion of saline. IRMI infusion of QC-13 increased blood pressure in Ang II treated mice to $164 \pm 2(\mathrm{p}<0.05)$. Renal medullary superoxide production in Ang II treated mice was significantly increased by infusion of QC-13 alone. Ang II treated mice receiving IRMI infusion of tempol had a blood pressure of $136 \pm 3 \mathrm{mmHg}$. Ang II treated mice receiving IRMI infusion of tempol and QC-13 had a significantly lower blood pressure $(142 \pm 2 \mathrm{mmHg}, \mathrm{p}<0.05)$ than mice receiving $\mathrm{QC}-13$ alone. The increase in renal medullary superoxide production was normalized by infusion of tempol alone or in combination with QC-13.
\end{abstract}

Conclusion-These results demonstrate that renal medullary interstitial blockade of HO-1 exacerbates Ang II-induced hypertension via a mechanism that is dependent on enhanced superoxide generation and highlight the important anti-oxidant function of HO-1 in the renal medulla.

\footnotetext{
*Direct Correspondence to: David E. Stec, Ph.D., Associate Professor, Department of Physiology \& Biophysics, University of Mississippi Medical Center, Jackson, MS 39216, Phone: 601-815-1859, Fax: 601-984-1817, dstec@umc.edu.

The Authors have no conflicts of interest to declare.
} 


\section{Keywords}

blood pressure; superoxide; renin; bilirubin; carbon monoxide

\section{INTRODUCTION}

Heme oxygenase (HO) is the enzyme responsible for the breakdown of heme into carbon monoxide (CO), biliverdin, and free iron. $\mathrm{HO}$ is present in two isoforms in the kidney. HO-2 is the constitutively expressed isoform of $\mathrm{HO}$ in the kidney, and the main isoform found under basal conditions (29). HO-1 is the inducible isoform of HO in the kidney (1). Several studies have demonstrated the importance of renal HO-1 in the regulation of blood pressure in response to high salt diet, angiotensin II infusion, and in genetic models of hypertension such as the spontaneously hypertensive rat $(16 ; 24 ; 33 ; 35)$.

Within the kidney, HO-1 expression in the renal medulla has been shown to play a critical role in the regulation of blood pressure and kidney function. For example, induction of HO-1 specifically in the renal medulla via intrarenal medullary interstitial infusion of the HO-1 inducer cobalt protoporyphrin (CoPP) prevented the development of angiotensin IIdependent hypertension (32). Moreover, HO-1 overexpression specifically in thick ascending loop of Henle (TALH) cells in the kidney attenuated the development of angiotensin II-induced hypertension by altering the levels of the sodium, potassium, 2 chloride co-transporter (26).

Previous studies from our group have demonstrated that renal medullary specific inhibition of HO-1 exacerbates angiotensin II-induced hypertension (4). The effect of renal medullary HO-1 inhibition on blood pressure in response to angiotensin-II dependent hypertension is similar to the blood pressure effect of HO-1 inhibition observed in response to a high sodium diet (16).

Previous studies have demonstrated that alterations in renal medullary HO activity are associated with an increase in reactive oxygen species (ROS) production and decreases in anti-oxidant proteins $(4 ; 33)$. Additional studies in cultured TALH cells have also demonstrated that overexpression of HO-1 attenuates angiotensin II-dependent ROS production (22). Despite the evidence demonstrating a link between renal medullary HO activity and ROS production, the anti-oxidant role of HO-1 in the regulation of blood pressure in response to angiotensin II-dependent hypertension is not known. The goal of this study was to determine the role of increased ROS production to the enhanced blood pressure effect of renal medullary HO-1 inhibition in response to angiotensin II-dependent hypertension. ROS production was blocked by intramedullary interstitial infusion (IRMI) of the superoxide dismutase mimetic Tempol in the presence and absence of inhibition of HO activity $(10 ; 23)$. 


\section{METHODS}

\section{Animals}

Experiments were performed on 16- to 24-week-old C57BL/6J mice purchased from Jackson Labs (Bar Harbor, ME). The mice were fed a standard diet containing $0.29 \% \mathrm{NaCl}$ and were provided water ad libitum. All animal protocols were approved by the Institutional Animal Care and Use Committee at the University of Mississippi Medical Center and performed in accordance with the Guide for the Care and Use of Laboratory Animals of the National Institutes of Health.

\section{Implantation of intrarenal medullary interstitial catheters}

All mice underwent unilateral nephrectomy of the right kidney to remove potential contributions of the non-infused kidney to the blood pressure response to experimental manipulations. After seven days, intramedullary interstitial catheters were implanted 1.5-2 $\mathrm{mm}$ into the left kidney as previously described $(5 ; 32)$. Saline was then infused through the catheter for a period of 3 days after which time the infusion was switched to Tempol $(6 \mathrm{mM}$ in saline) or QC-13, $(2 R, 4 R)$-2-[2-(4-chlorophenyl)ethyl]-2-[(1H-imidazol-1-yl)methyl]-4methyl-1,3-dioxolane hydrochloride, $(25 \mu \mathrm{M}$, in saline), in some mice. Previous studies in rats and dogs served as the basis for the concentration of Tempol use for chronic intramedullary interstitial infusion $(2 ; 17)$. The concentration of QC-13 use for IRMI infusion was based on previous studies demonstrating a significant decrease in renal medullary $\mathrm{HO}$ activity $(4 ; 5)$ After 2 days, some mice receiving Tempol were additionally infused for with QC-13. Infusions were continued throughout the entire experimental protocol. Mice received their final combination of QC-13 and Tempol for two days after which osmotic minipumps delivering either vehicle (saline) or Ang II at a rate of 1 $\mu \mathrm{g} / \mathrm{kg} / \mathrm{min}$ were implanted subcutaneously.

\section{Blood Pressure}

Blood pressure was directly measured via microrenathane catheters implanted into the carotid artery using aseptic surgical technique after implantation of angiotensin II osmotic minipumps as previously described (33). This method is consistent with recommendations of the American Heart Association for measuring blood pressure in conscious animals (14). The mice were allowed two days to recover from surgery and then mean arterial blood pressure (MAP) was recorded from conscious, freely moving mice five hours per day for three consecutive days. Blood pressures are presented as the daily average pressure over the entire three-day recording period. Mice were euthanized after blood pressure measurement at which time body and organ weights were measured. Tissues were frozen in liquid nitrogen and stored at $-80^{\circ} \mathrm{C}$ until use.

\section{Measurement of Renal Medullary Superoxide Production}

Superoxide production in the renal medulla was measured using the lucigenin technique as previously described (33). Briefly, infused kidneys were removed and separated into renal cortex and medulla. The medulla was then homogenized (1:8 wt/vol) in RIPA buffer (PBS, $1 \%$ Nonidet P-40, $0.5 \%$ sodium deoxycholate, $0.1 \%$ SDS, and a protease inhibitor cocktail; 
Sigma Chemical). The samples were centrifuged at $12,000 \mathrm{~g}$ for $20 \mathrm{~min}$ at $4^{\circ} \mathrm{C}$. The supernatant was incubated with lucigenin at a final concentration of $5 \mu \mathrm{M}$ and samples were allowed to equilibrate for $3 \mathrm{~min}$ in the dark, and luminescence was measured every second for 5-15 min with a luminometer (Berthold, Oak Ridge, TN). Luminescence was recorded as relative light units (RLU) per min. After the initial measurement, NADPH was added to a final concentration of $100 \mu \mathrm{M}$ and measurements repeated as above to give the basal plus NADPH-mediated superoxide production. An assay blank with no homogenate but containing lucigenin was subtracted from the reading before transformation of the data. The protein concentration was measured using a Bio-Rad protein assay with BSA standards. The data are expressed as RLU per min per milligram protein.

\section{Statistics}

Mean values \pm SE are presented. Significant differences between mean values were determined by 2 way ANOVA followed by a post hoc test (Studen-Newman-Keuls). A $P<0.05$ was considered to be significant.

\section{RESULTS}

\section{Intrarenal medullary interstitial infusion (IRMI) of Tempol prevents the QC-13 mediated increase in blood pressure in angiotensin II-dependent hypertensive mice}

Blood pressures averaged $150 \pm 3 \mathrm{mmHg}$ in Ang II-treated mice receiving IRMI infusion of saline. IRMI infusion of Tempol alone in Ang II treated mice attenuated the rise in blood pressure to $136 \pm 3 \mathrm{mmHg}$ ( $\mathrm{p}<0.05$ ). IRMI infusion of QC-13 alone increased Ang IIdependent hypertension to $164+2(\mathrm{p}<0.05)$ and IRMI infusion of Tempol along with QC-13 significantly attenuated the increase in blood pressure to $142+2 \mathrm{mmHg}(\mathrm{p}<0.05)$ in mice infused with Ang II (Figure 1).

\section{Intrarenal medullary interstitial infusion (IRMI) of Tempol normalizes cardiac hypertrophy in QC-13 infused angiotensin II hypertensive mice}

Cardiac hypertrophy determined by the ratio of heart weight to body weight (HW:BW) was significantly increased to $6.9+0.2$ as compared to $6.1+0.2 \mathrm{mg} / \mathrm{g}$ in Ang II treated, IRMI QC-13 mice versus IRMI vehicle treated mice (Figure 2). Ang II treated mice receiving IRMI Tempol infused with QC-13 resulted in a normalization of cardiac hypertrophy to levels that were similar to those observed in Ang II + IRMI vehicle-treated mice (Figure 2). IRMI infusion of Tempol alone did result in a small but not statistically significant decrease in cardiac hypertrophy as compared to Ang II + IRMI vehicle mice (Figure 2).

\section{Intrarenal medullary interstitial infusion of Tempol prevents the QC-13 mediated increase in renal medullary superoxide production in angiotensin II-dependent hypertensive mice}

IRMI infusion of QC-13 enhanced basal superoxide production in the renal medulla of Ang II-treated mice as compared to mice which received IRMI infusion of saline (Figure 3A). IRMI infusion of Tempol alone or in combination with QC-13 significantly reduced basal superoxide production in Ang II treated mice as compared to mice that received IRMI vehicle or QC-13 alone (Figure 3A). 
IRMI infusion of QC-13 also enhanced NADPH-stimulated superoxide production in the renal medulla of Ang II-treated mice as compared to mice which received IRMI infusion of saline (Figure 3B). IRMI infusion of Tempol alone or in combination with QC-13 significantly reduced NADPH-stimulated superoxide production in Ang II treated mice as compared to mice that received IRMI vehicle or QC-13 alone (Figure 3B).

\section{DISCUSSION}

This study was designed to determine the role of enhanced renal medullary superoxide production to the exacerbation of blood pressure with intramedullary blockade of HO-1. Several previous studies have examined the antioxidant role of renal medullary heme oxygenase. Renal medullary induction of HO-1 decreases angiotensin II-mediated superoxide production and increases the levels of catalase protein $(32 ; 33)$. Overexpression of HO-1 in thick ascending loop of Henle cells also decreases angiotensin-II mediated oxidative injury (22). We recently reported that renal medullary interstitial blockade of heme oxygenase with the imidazole-dioxolane HO-1 inhibitor, QC-13, exacerbated angiotensin IIdependent hypertension (4). Unlike traditional porphyrin-based HO inhibitors, IRMI infusion of QC-13 is not associated with induction of HO-1 or HO-2 protein levels in the renal medulla $(4 ; 5)$. Significant increases in renal medullary superoxide production, as well as significant decreases in antioxidant enzymes catalase and manganese superoxide dismutase (MnSOD), were observed in mice receiving intramedullary interstitial infusion of QC-13 (4). The results of the present study support the hypothesis that the further increase in renal medullary superoxide production resulting from inhibition of $\mathrm{HO}$ is responsible for the augmentation of Ang II-dependent hypertension. Blockade of the increase in superoxide production with the SOD mimetic, Tempol, was able to prevent the increase in blood pressure in response to inhibition of $\mathrm{HO}$ in Ang II-infused mice. It is interesting to note that while IRMI infusion of QC-13 increases renal medullary superoxide levels in normal mice; however, it does not result in any significant increase in blood pressure (4). This finding suggests that in the setting of Ang II-dependent hypertension further increases in renal medullary superoxide production due to $\mathrm{HO}$ inhibition can result in elevations in blood pressure.

In the current study, IRMI administration of Tempol blocked both basal and NADPHdependent superoxide production in the renal medulla of Ang II and Ang II + QC-13 infused mice. QC-13 administration alone increases both basal and NADPH-dependent superoxide production in the renal medulla of Ang II-infused mice. These results demonstrate the important role of $\mathrm{HO}$ and its metabolites in the regulation of basal levels of superoxide production from sources such as xanthine oxidase, uncoupled nitric oxide synthase or increased heme levels. Previous studies have demonstrated that Ang II infusion results in significant increases in renal medullary heme content which can be source of basal superoxide production $(32 ; 33)$. IRMI administration of QC-13 also resulted in the enhancementt of NADPH-mediated superoxide production which was completely abolished by Tempol treatment. HO has been previously shown to be an important antioxidant enzyme in several tissues. The consensus is that $\mathrm{HO}$ acts as an antioxidant primarily through generation of bilirubin. Bilirubin is a very powerful antioxidant molecule $(27 ; 28)$. Several studies have demonstrated that bilirubin can decrease superoxide levels through direct 
scavenging (6). However, bilirubin has also been reported to inhibit directly NADPH oxidase activity $(9 ; 15 ; 30)$. While bilirubin generation has been believed to be responsible for the antioxidant actions of HO-1 induction, it is also possible that generation of carbon monoxide (CO) may also confer antioxidant actions (13). Cultured thick ascending loop of Henle cells in which bilirubin generation is inhibited by knockdown of biliverdin reductase still exhibit HO-1 induced decreases in angiotensin II-mediated superoxide production presumably through the generation of $\mathrm{CO}(36)$. $\mathrm{CO}$ has also been shown to inhibit directly NADPH oxidase-mediated superoxide production $(18 ; 34)$. Thus, it is possible that induction of HO-1 in the renal medulla decreases superoxide levels through increased production of both bilirubin and $\mathrm{CO}$.

Increases in renal medullary superoxide production can result in hypertension through two distinct mechanisms. The first being a direct effect of transport of sodium and water in the medullary thick ascending loop of Henle (TALH). Superoxide has both direct and indirect actions to increase sodium transport in the TALH. Superoxide has been demonstrated to regulate directly sodium transport in the TALH by stimulating the sodium, potassium, two chloride (NKCC2) transporter (12; 20). Angiotensin II can also regulate sodium reabsorption through enhanced superoxide production in the TALH, which stimulates greater sodium and water reabsorption (25). It is likely that blockade of HO in the renal medulla via infusion of QC-13 enhances angiotensin II-mediated superoxide production in the TALH due to increased sodium and water reabsorption. Superoxide can also affect sodium reabsorption in the TALH through its interaction with nitric oxide (NO) production. NO can reduce sodium reabsorption in the TALH through inhibition of both the NKCC2 transporter and the sodium-potassium ATPase $(11 ; 31)$. However, enhanced superoxide production in the TALH has been demonstrated to decrease the bioavailability of NO further enhancing sodium reabsorption in this nephron segment (19). It is likely that inhibition of $\mathrm{HO}$ activity in the renal medulla decreases NO bioavailability through enhancement of superoxide production further stimulating sodium reabsorption in the TALH and resulting in a greater increase in blood pressure in response to Ang II.

One of the major consequences of hypertension is the effect that it has on peripheral organs such as the heart and kidneys resulting in target organ injury. Cardiac hypertrophy in the IRMI QC-13 + Ang II-infused mice was significantly increased in accordance with the further rise in blood pressure in these mice. IRMI infusion of Tempol either alone or in combination with QC-13 infusion resulted in a significant decrease in blood pressure, but no further decrease in cardiac hypertrophy as compared to IRMI vehicle treated Ang II-infused mice although it did prevent the increase in cardiac hypertrophy in response to IRMI QC-13 treatment. The effect of Ang II to directly promote cardiac hypertrophy independent of hypertension is a very controversial area. Several studies have demonstrated that Ang II promotes cardiac hypertrophy through increases in blood pressure as well as independently of blood pressure $(3 ; 7 ; 8 ; 21)$. Our results in the IRMI Tempol treated mice support a direct effect of Ang II to promote cardiac hypertrophy at least in the time frame of the current study; however, since more direct measures of cardiac hypertrophy such as echocardiography or imaging of the heart were not performed in the current study these results need to be further verified. 
In summary, our results further establish the important antioxidant role for $\mathrm{HO}$ in the renal medulla through its effects on medullary superoxide production in Ang II-dependent hypertension. Strategies to enhance renal medullary HO levels may prove to be beneficial in several forms of hypertension in which the levels of renal medullary superoxide production are believed to play a significant role in the maintenance of hypertension.

\section{Acknowledgments}

The authors would like to acknowledge the support of grants from the National Heart, Lung and Blood Institute, PO1HL-51971, and 1RO1HL108618-01.

\section{References}

1. Abraham NG, Kappas A. Pharmacological and clinical aspects of heme oxygenase. Pharmacol Rev. 2008; 60:79-127. [PubMed: 18323402]

2. Ahmeda AF, Johns EJ. The regulation of blood perfusion in the renal cortex and medulla by reactive oxygen species and nitric oxide in the anaesthetised rat. Acta Physiol (Oxf). 2012; 204:443-450. [PubMed: 21827636]

3. Crowley SD, Gurley SB, Herrera MJ, Ruiz P, Griffiths R, Kumar AP, Kim HS, Smithies O, Le TH, Coffman TM. Angiotensin II causes hypertension and cardiac hypertrophy through its receptors in the kidney. Proc Natl Acad Sci U S A. 2006; 103:17985-17990. [PubMed: 17090678]

4. Csongradi E, Storm MV, Stec DE. Renal Inhibition of Heme Oxygenase-1 Increases Blood Pressure in Angiotensin II-Dependent Hypertension. Int J Hypertens. 2012; 2012:497213. [PubMed: 22164328]

5. Csongradi E, Vera T, Rimoldi JM, Gadepalli RS, Stec DE. In vivo inhibition of renal heme oxygenase with an imidazole-dioxolane inhibitor. Pharmacol Res. 2010; 61:525-530. [PubMed: 20338241]

6. Datla SR, Dusting GJ, Mori TA, Taylor CJ, Croft KD, Jiang F. Induction of heme oxygenase-1 in vivo suppresses NADPH oxidase derived oxidative stress. Hypertension. 2007; 50:636-642. [PubMed: 17679649]

7. Dominiczak AF, Devlin AM, Brosnan MJ, Anderson NH, Graham D, Clark JS, McPhaden A, Hamilton CA, Reid JL. Left ventricular hypertrophy and arterial blood pressure in experimental models of hypertension. Adv Exp Med Biol. 1997; 432:23-33. [PubMed: 9433508]

8. Dostal DE, Baker KM. Angiotensin II stimulation of left ventricular hypertrophy in adult rat heart. Mediation by the AT1 receptor. Am J Hypertens. 1992; 5:276-280. [PubMed: 1533768]

9. Fujii M, Inoguchi T, Sasaki S, Maeda Y, Zheng J, Kobayashi K, Takayanagi R. Bilirubin and biliverdin protect rodents against diabetic nephropathy by downregulating $\mathrm{NAD}(\mathrm{P}) \mathrm{H}$ oxidase. Kidney Int. 2010; 78:905-919. [PubMed: 20686447]

10. Hahn SM, Tochner Z, Krishna CM, Glass J, Wilson L, Samuni A, Sprague M, Venzon D, Glatstein $\mathrm{E}$, Mitchell JB. Tempol, a stable free radical, is a novel murine radiation protector. Cancer Res. 1992; 52:1750-1753. [PubMed: 1551104]

11. Herrera M, Ortiz PA, Garvin JL. Regulation of thick ascending limb transport: role of nitric oxide. Am J Physiol Renal Physiol. 2006; 290:F1279-F1284. [PubMed: 16682483]

12. Juncos R, Garvin JL. Superoxide enhances Na-K-2Cl cotransporter activity in the thick ascending limb. Am J Physiol Renal Physiol. 2005; 288:F982-F987. [PubMed: 15821259]

13. Kelsen S, Patel BJ, Parker LB, Vera T, Rimoldi JM, Gadepalli RS, Drummond HA, Stec DE. Heme oxygenase attenuates angiotensin II-mediated superoxide production in cultured mouse thick ascending loop of Henle cells. Am J Physiol Renal Physiol. 2008; 295:F1158-F1165. [PubMed: 18701634]

14. Kurtz TW, Griffin KA, Bidani AK, Davisson RL, Hall JE. Recommendations for blood pressure measurement in humans and experimental animals. Part 2: Blood pressure measurement in experimental animals: a statement for professionals from the subcommittee of professional and 
public education of the American Heart Association council on high blood pressure research. Hypertension. 2005; 45:299-310. [PubMed: 15611363]

15. Lanone S, Bloc S, Foresti R, Almolki A, Taille C, Callebert J, Conti M, Goven D, Aubier M, Dureuil B, El Benna J, Motterlini R, Boczkowski J. Bilirubin decreases nos2 expression via inhibition of $\mathrm{NAD}(\mathrm{P}) \mathrm{H}$ oxidase: implications for protection against endotoxic shock in rats. FASEB J. 2005; 19:1890-1892. [PubMed: 16129699]

16. Li N, Yi F, Dos Santos EA, Donley DK, Li PL. Role of renal medullary heme oxygenase in the regulation of pressure natriuresis and arterial blood pressure. Hypertension. 2007; 49:148-154. [PubMed: 17075028]

17. Majid DS, Nishiyama A, Jackson KE, Castillo A. Inhibition of nitric oxide synthase enhances superoxide activity in canine kidney. Am J Physiol Regul Integr Comp Physiol. 2004; 287:R27R32. [PubMed: 15044181]

18. Matsumoto H, Ishikawa K, Itabe H, Maruyama Y. Carbon monoxide and bilirubin from heme oxygenase-1 suppresses reactive oxygen species generation and plasminogen activator inhibitor-1 induction. Mol Cell Biochem. 2006; 291:21-28. [PubMed: 16625420]

19. Ortiz PA, Garvin JL. Interaction of $\mathrm{O}(2)(-)$ and $\mathrm{NO}$ in the thick ascending limb. Hypertension. 2002; 39:591-596. [PubMed: 11882614]

20. Ortiz PA, Garvin JL. Superoxide stimulates $\mathrm{NaCl}$ absorption by the thick ascending limb. Am J Physiol Renal Physiol. 2002; 283:F957-F962. [PubMed: 12372771]

21. Paradis P, Dali-Youcef N, Paradis FW, Thibault G, Nemer M. Overexpression of angiotensin II type I receptor in cardiomyocytes induces cardiac hypertrophy and remodeling. Proc Natl Acad Sci U S A. 2000; 97:931-936. [PubMed: 10639182]

22. Quan S, Yang L, Shnouda S, Schwartzman ML, Nasjletti A, Goodman AI, Abraham NG. Expression of human heme oxygenase-1 in the thick ascending limb attenuates angiotensin IImediated increase in oxidative injury. Kidney Int. 2004; 65:1628-1639. [PubMed: 15086901]

23. Reddan J, Sevilla M, Giblin F, Padgaonkar V, Dziedzic D, Leverenz V. Tempol and deferoxamine protect cultured rabbit lens epithelial cells from $\mathrm{H} 2 \mathrm{O} 2$ insult: insight into the mechanism of $\mathrm{H} 2 \mathrm{O} 2-$ induced injury. Lens Eye Toxic Res. 1992; 9:385-393. [PubMed: 1338754]

24. Sacerdoti D, Escalante B, Abraham NG, McGiff JC, Levere RD, Schwartzman ML. Treatment with tin prevents the development of hypertension in spontaneously hypertensive rats. Science. 1989; 243:388-390. [PubMed: 2492116]

25. Silva GB, Garvin JL. Angiotensin II-dependent hypertension increases Na transport-related oxygen consumption by the thick ascending limb. Hypertension. 2008; 52:1091-1098. [PubMed: 19001187]

26. Stec DE, Drummond HA, Gousette MU, Storm MV, Abraham NG, Csongradi E. Expression of heme oxygenase-1 in thick ascending loop of henle attenuates angiotensin II-dependent hypertension. J Am Soc Nephrol. 2012; 23:834-841. [PubMed: 22323644]

27. Stocker R. Antioxidant activities of bile pigments. Antioxid Redox Signal. 2004; 6:841-849. [PubMed: 15345144]

28. Stocker R, Yamamoto Y, McDonagh AF, Glazer AN, Ames BN. Bilirubin is an antioxidant of possible physiological importance. Science. 1987; 235:1043-1046. [PubMed: 3029864]

29. Stout JM, Gousset MU, Drummond HA, Gray W III, Pruett BE, Stec DE. Sex-specific effects of heme oxygenase-2 deficiency on renovascular hypertension. J Am Soc Hypertens. 2013

30. Taille C, El Benna J, Lanone S, Dang MC, Ogier-Denis E, Aubier M, Boczkowski J. Induction of heme oxygenase- 1 inhibits $\mathrm{NAD}(\mathrm{P}) \mathrm{H}$ oxidase activity by down-regulating cytochrome b558 expression via the reduction of heme availability. J Biol Chem. 2004; 279:28681-28688. [PubMed: 15123630]

31. Varela M, Herrera M, Garvin JL. Inhibition of Na-K-ATPase in thick ascending limbs by NO depends on O2- and is diminished by a high-salt diet. Am J Physiol Renal Physiol. 2004; 287:F224-F230. [PubMed: 15113751]

32. Vera T, Kelsen S, Stec DE. Kidney-specific induction of heme oxygenase-1 prevents angiotensin II hypertension. Hypertension. 2008; 52:660-665. [PubMed: 18695146] 
33. Vera T, Kelsen S, Yanes LL, Reckelhoff JF, Stec DE. HO-1 induction lowers blood pressure and superoxide production in the renal medulla of angiotensin II hypertensive mice. Am J Physiol Regul Integr Comp Physiol. 2007; 292:R1472-R1478. [PubMed: 17194725]

34. Wang X, Wang Y, Kim HP, Nakahira K, Ryter SW, Choi AM. Carbon monoxide protects against hyperoxia-induced endothelial cell apoptosis by inhibiting reactive oxygen species formation. $\mathrm{J}$ Biol Chem. 2007; 282:1718-1726. [PubMed: 17135272]

35. Yang L, Quan S, Nasjletti A, Laniado-Schwartzman M, Abraham NG. Heme oxygenase-1 gene expression modulates angiotensin II-induced increase in blood pressure. Hypertension. 2004; 43:1221-1226. [PubMed: 15166181]

36. Young SC, Storm MV, Speed JS, Kelsen S, Tiller CV, Vera T, Drummond HA, Stec DE. Inhibition of biliverdin reductase increases ANG II-dependent superoxide levels in cultured renal tubular epithelial cells. Am J Physiol Regul Integr Comp Physiol. 2009; 297:R1546-R1553. [PubMed: 19759334] 


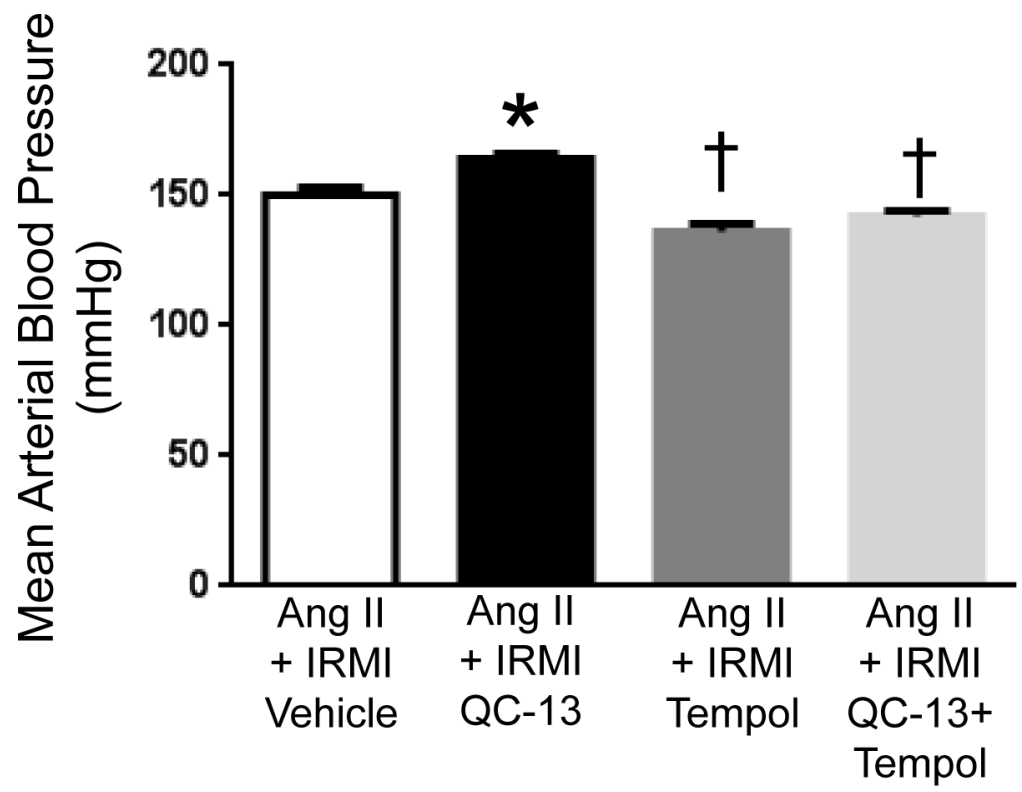

Figure 1.

Blood pressure response in each of the experimental groups measured on days 7-10 post implantation of angiotensin II containing osmotic minipumps, $n=6 /$ group. * ${ }^{*}$ significant $(\mathrm{P}<0.05)$ difference as compared to the corresponding value in Ang II + IRMI vehicle mice. $\dagger=$ significant $(\mathrm{P}<0.05)$ difference as compared to the corresponding value in Ang II + IRMI QC-13 mice. 


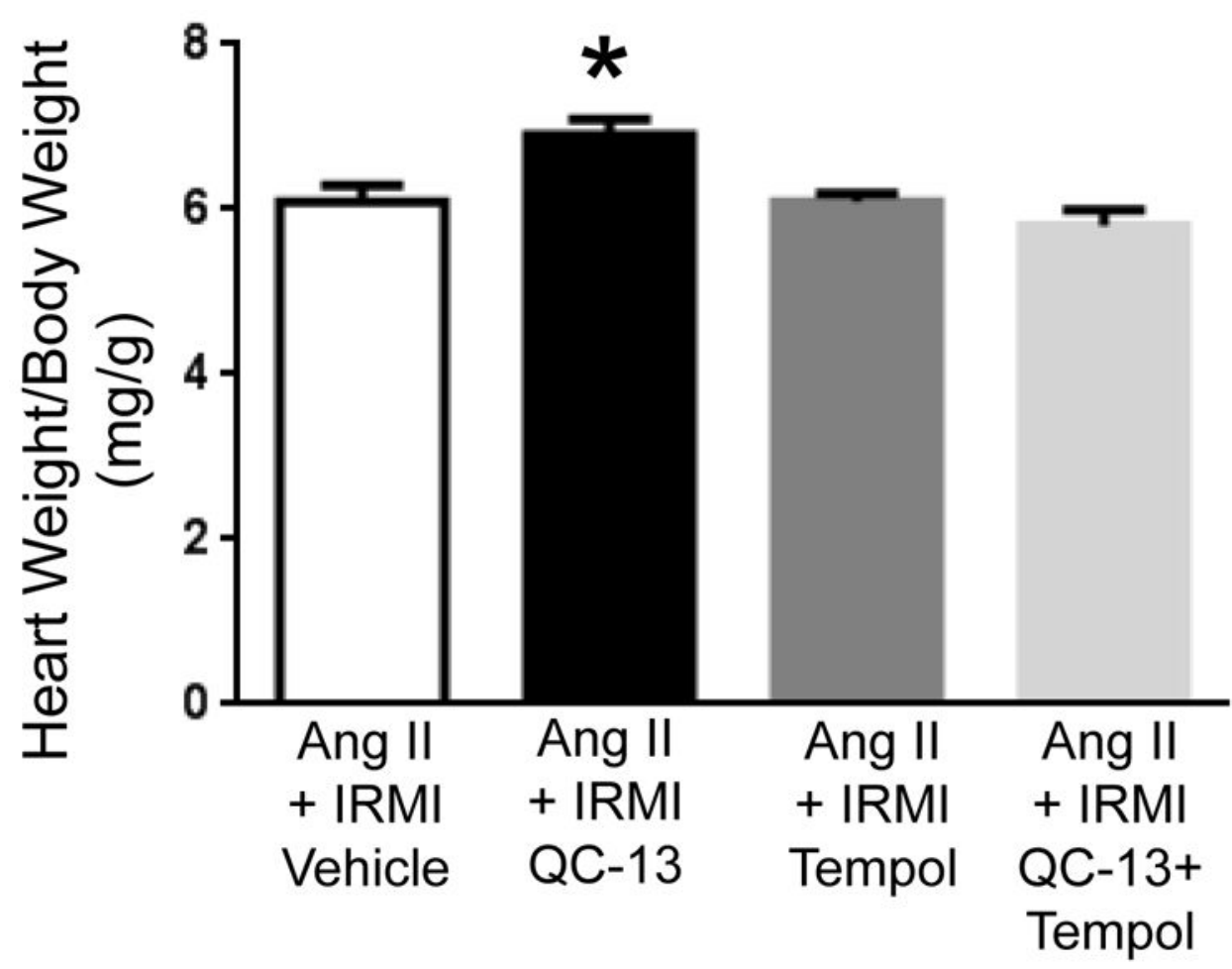

Figure 2.

Cardiac hypertrophy in each of the experimental groups, $\mathrm{n}=6 /$ group $*=$ significant $(\mathrm{P}<0.05)$ difference as compared to corresponding value in Ang II + IRMI vehicle mice. 

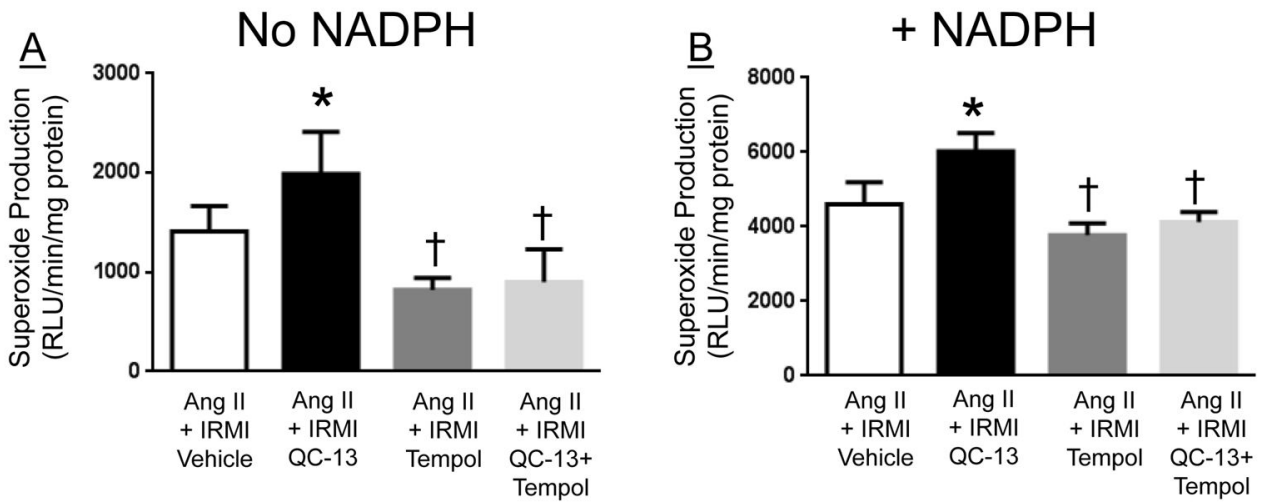

Figure 3.

Quantitation of renal medullary superoxide generation in the absence, Panel A, and presence, Panel B, of NADPH. * = significant $(\mathrm{P}<0.05)$ difference as compared to the corresponding value in Ang II + IRMI vehicle mice. $\dagger=$ significant $(\mathrm{P}<0.05)$ difference as compared to the corresponding value in Ang II + IRMI QC-13 mice, n=6/group. 